\title{
Reliability and Validity of the Turkish Version of the ABILHAND Questionnaire in Rheumatoid Arthritis Individuals, Based on Rasch Analysis
}

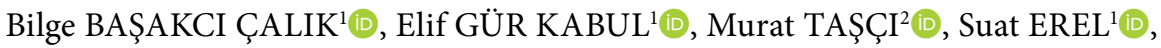 \\ İbrahim Engin ŞİMŞEK ${ }^{3}$, Pervin DEMİR ${ }^{4}$, Veli ÇOBANKARA² ${ }^{2}$ \\ ${ }^{1}$ School of Physical Therapy and Rehabilitation, Pamukkale University, Denizli, Turkey \\ ${ }^{2}$ Department of Rheumatology, Medical Faculty of Pamukkale University, Denizli, Turkey \\ ${ }^{3}$ School of Physical Therapy and Rehabilitation, Dokuz Eylül University, Izmir, Turkey \\ ${ }^{4}$ Department of Biostatistics and Medical Informatics, Yıldırım Beyazıt University, Ankara, Turkey
}

\begin{abstract}
Objectives: This study aims to assess the reliability and validity of the Turkish version of the ABILHAND questionnaire in individuals with rheumatoid arthritis (RA) [ABILHAND-RA (TR)] using the Rasch analysis.

Materials and methods: A total 90 individuals ( 15 males, 75 females; mean age $51.8 \pm 10.9$ years; range, 20 to 65 years) diagnosed as RA according to the criteria of the American College of Rheumatology were included. The ABILHAND-RA (TR) was used to determine manual ability, while disease activity was evaluated by the use of Disease Activity Score 28 (DAS28). Jamar hand dynamometer and pinch-meter were used to examine grip and pinch strength of the participants. Nine Hole Peg Test (NHPT) and Duruoz Hand Index (DHI) measured hand disability level. Nottingham Health Profile (NHP) was used to assess quality of life. ABILHAND-RA (TR) results were analyzed using the Rasch analysis method.

Results: Item 20 was excluded from the 27 -item ABILHAND-RA (TR) as $96 \%$ of the individuals rated this item as "easy". The new set of 18 items (7 subtests and 11 items) were found to sustain item invariance and fit to the Rasch model. Significant relationships were found between ABILHAND-RA (TR) and DAS28, bilateral grip strength, NHPT dominant side results, DHI, and NHP.

Conclusion: Turkish version of the ABILHAND-RA was found to be clinically valid, reliable, and sensitive enough to be used in clinical evaluations, rehabilitation interventions, and for progression follow-up in individuals with RA.
\end{abstract}

Keywords: Activities of daily living, questionnaires, rheumatoid arthritis, upper extremity.

Rheumatoid arthritis (RA) is a chronic and systemic inflammatory disease with accompanying articular and extraarticular symptoms. ${ }^{1}$ It is the most common chronic inflammatory polyarthritis in adults affecting $1 \%$ of the population. ${ }^{2}$ According to a study conducted in 2006, prevalence of RA in Turkey was found to be $0.36 \% .^{3}$

Rheumatoid arthritis may affect joints with symmetrical involvement; however, it was reported that relatively small joints such as phalangeal joints and wrist may be affected more frequently in early phases. ${ }^{4}$ It is thought that hand and wrist are the mainly affected joints in 80 to $90 \%$ of the individuals with RA; representing symptoms of inflammation, mild to severe deformities, pain, muscle weakness, and range of motion limitation that eventually lead to functional loss. ${ }^{5}$

Received: October 09, 2018 Accepted: January 30, 2019 Published online: April 26, 2019

Correspondence: Bilge Başakcı Çalık, pHD. Pamukkale Üniversitesi Fizik Tedavi ve Rehabilitasyon Yüksekokulu, 20070 Kınıklı, Denizli, Turkey. Tel: +90 505 - 4061287 e-mail: fztbilge@hotmail.com 
It is considered that in addition to hand grip, pinch grip, and range of motion as objective measurements, the most reliable way to assess functional capacity of an individual is to evaluate perceived functional level using targeted tools as Nine Hole Peg Test (NHPT) and Duruoz Hand Index (DHI). ${ }^{6}$ During the last decade, various evaluation tools (i.e., arthritis impact measurement scale, disability of the arm, shoulder and hand questionnaire, and Michigan hand outcome questionnaire) have commonly been used in clinical research for measuring the outcomes of related interventions. The aim of using evaluation tools is defined as to identify the overall difficulty in performing daily activities that is usually referred to as disability. ${ }^{7}$ However, mostly, these generic tools were not designed to assess rheumatoid hand by focusing on the functional outcome of an intervention targeted to rehabilitate hand skill and/or to increase functional capacity of an individual.

ABILHAND questionnaire was developed as a hand skill measurement tool based on individuals' perceptions. It was initially developed and validated for persons with $\mathrm{RA}^{8}$ and then for persons with chronic stroke $e^{9}$ as well as for several other diagnoses. ${ }^{10-13}$ ABILHAND questionnaire focuses on inventories that best represent hand activities. Some of the items were chosen from current tools, whereas others were designed to enrich the variety of hand activities. ABILHAND questionnaire, which was not designed to evaluate hand function specific to RA, originally contains 56 items. Following a successive Rasch analysis conducted by Durez et al., ${ }^{14}$ the number of items was reduced to 27 , which were found to be much more sensitive and appropriate for assessing and discriminating hand skills.

Manual ability may be defined as the capacity of performing daily activities that require the use of upper extremities. Manual ability is evaluated by questionnaires that determine the perceived difficulties during activity performance. Linear measurement of manual ability is possible only with the help of obtained raw scores that are suitable for a given Rasch model..$^{9}$ Recently, the tendency to use Rasch models has increased due to its ability to ease the development and validation of outcome measurement tools. ${ }^{15}$ Rasch analysis helps to convert ordinal scores into linear measurements and gather psychometric data that are otherwise impossible to obtain by using classical test theories. ${ }^{9,16,17}$ The most significant advantage of linear measurements is their ability to provide equally distributed units that allow obtaining correct results while performing interand/or intra-individual comparisons. ${ }^{18}$ Equivalent scores show the level of equivalency of the measured construct in different populations, which is a necessity to represent the cultural stability of a given measure. ${ }^{19}$ Therefore, in this study, we aimed to assess the reliability and validity of the ABILHAND-RA (TR) using the Rasch analysis.

\section{MATERIALS AND METHODS}

A total of 90 individuals (15 males, 75 females; mean age $51.8 \pm 10.9$ years; range 20 to 65 years) with RA were recruited between September 2016 and June 2017 from Pamukkale University Faculty of Medicine Rheumatology Outpatient Clinic. RA diagnosis was established according to the classification criteria of the American College of Rheumatology. ${ }^{20}$ Inclusion criteria were (i) being aged between 20-65 years, (ii) having stable medical treatment for the last six months prior to the study, and (iii) being fluent in Turkish language. Exclusion criteria were (i) having a neurological condition affecting hand functions (peripheral nerve lesion, prior trauma and/or surgery, or cerebrovascular condition), (ii) having any psychiatric condition that may affect cooperation, or (iii) having heart failure and/or pulmonary pathology that may affect the performance in daily activities. The study protocol was approved for non-interventional clinical investigations by the Pamukkale University Faculty of Medicine Ethics Committee (decision no: 60116787-020/2755, dated 01 November 2017). A written informed consent was obtained from each participant. The study was conducted in accordance with the principles of the Declaration of Helsinki. Demographic characteristics of the individuals were collected via a structured interview. All participants were evaluated in the outpatient clinic by the same researcher. Disease activity was calculated using Disease Activity Score 28 (DAS28). ${ }^{21}$ Functional tests were performed in a single session that lasted about 45 to 60 minutes.

Manual ability was evaluated using the ABILHAND-RA (TR), an inventory of 27 common manual activities, rated as: $0=$ impossible, 
$1=$ difficult, $2=$ easy. The volunteer was asked to evaluate the ease of performing the activities of daily living regardless of the limb(s) actually used and the strategy used. ${ }^{8}$

Maximum voluntary handgrip, fingertip grip, lateral grip, and tripod grip force were measured using the Jamar dynamometer and a pinchmeter according to the procedure explained by Mathiowetz et al. ${ }^{22}$ Manuel dexterity was assessed using the NHPT. ${ }^{23}$ All tests were performed for both hands starting from the less affected hand defined by the individuals themselves.

To evaluate disability of the hand, individuals completed the DHI that comprises of 18 questions. DHI consists of questions that are divided into five categories as kitchen, dressing, hygiene, in the office, and other activities. Answers are structured and scored as: "Yes, without difficulty" $(=0)$, "Yes, with a little difficulty" (=1), "Yes, with some difficulty" $(=2)$, "Yes, with much difficulty" $(=3)$, "Nearly impossible to do" (=4), "Impossible" (=5). Total score is the sum of all answers and ranges from 0 to 90 . Higher score indicates disrupted hand functions. ${ }^{24}$

The health related quality of life was evaluated by using the Nottingham Health Profile (NHP). NHP is comprised of 38 items where each item is answered as "Yes" or "No". Six categories were evaluated within NHP as energy level, pain, emotional reactions, sleep, social isolation, and physical skill. Total score ranges between 0 and 100. A higher score indicates lower quality of life. ${ }^{25}$ Kucukdeveci et al. ${ }^{26}$ conducted the Turkish version study of NHP previously.

During ABILHAND questionnaire's crosscultural adaptation process, previously recommended procedures were followed in five stages. ${ }^{27,28}$ Firstly, the questionnaire was translated from English to Turkish by two different independent translators, whose native language was Turkish, and then both translations were synthesized into one. Secondly, other two independent translators (native in English language) who were unaware of the original items performed back-translations of the previously obtained Turkish translation of the questionnaire. After the translations were completed, four physiotherapists experienced in RA, who did not participate in the translation processes, held a consensus meeting and prepared the pre-final version. Lastly, the pre-final version of ABILHAND-RA (TR) was administered to 10 individuals with RA to evaluate comprehensibility and to determine other linguistic fine-tuning. During these interviews, no conflicts were obtained related to the comprehension or clarity of the items. The 27-item ABILHAND-RA (TR) was provided in Appendix 1.

\section{Statistical analysis}

Internal construct validity and external construct validity (convergent validity) were determined by using the Rasch analysis (partial credit Rasch model) and Spearman's rank correlation coefficient (rho), respectively. ${ }^{29-31}$ If any significant relationship was identified, the rho value was determined as "no relationship" or "insignificant relationship" between the values $p=0.00-0.19$, "weak (low) relationship" between $p=0.20-0.39$, "average relationship" between $p=0.40-0.69$, "strong (high) relationship" between $\mathrm{p}=0.70-0.89$ and "very strong relationship" between $p=0.90-1.0 .{ }^{32}$ The relationship between questionnaire score and demographical data was analyzed using the appropriate Mann-Whitney U test or Spearman's rho. Wilcoxon signed-rank test results were provided for grip test comparisons.

Reliability was investigated by using person separation index (PSI). ${ }^{33,34}$ Validities over 0.70 and over 0.85 were accepted as sufficient for group level and individual level analysis, respectively. ${ }^{35}$ Intra-class correlation coefficient (ICC, one-way random model) was used to evaluate test-retest reliability. ${ }^{36}$ The interpretation of ICC score was as follows: under $0.50=$ poor reliability, between $0.50-0.75=$ moderate reliability, between $0.76-0.90=$ good reliability, over $0.90=$ excellent reliability. ${ }^{37}$

The IBM SPSS version 21.0 software (IBM Corp., Armonk, New York, USA) and Rasch Unidimensional Measurement Model 2020 program (RUMM, Perth, Western Australia) was used to perform statistical analyses and calculations. Statistical significance value was set at $p<0.05$.

\section{Investigation of Rasch model assumptions $^{38,39}$}

- The threshold ordering of polytomous items was investigated with the help of threshold graphs.

- Local independence of items: Residual item correlation over 0.3 or higher was accepted as local dependence. 


\begin{tabular}{|c|c|c|c|c|c|}
\hline Variables & $\mathrm{n}$ & $\%$ & Mean \pm SD & Median & Min-Max \\
\hline Age (year) & & & $51.8 \pm 10.9$ & 54 & $20-65$ \\
\hline $\begin{array}{l}\text { Gender } \\
\text { Female } \\
\text { Male }\end{array}$ & $\begin{array}{l}75 \\
15\end{array}$ & $\begin{array}{l}83.3 \\
16.7\end{array}$ & & & \\
\hline $\begin{array}{l}\text { Dominant hand } \\
\text { Right } \\
\text { Left }\end{array}$ & $\begin{array}{c}81 \\
9\end{array}$ & $\begin{array}{l}90.0 \\
10.0\end{array}$ & & & \\
\hline Body mass index $\left(\mathrm{kg} / \mathrm{m}^{2}\right)$ & & & $28.1 \pm 6.1$ & 27.4 & $17.8-58.8$ \\
\hline Disease activity score $28(\mathrm{n}=64)$ & & & $2.90 \pm 1.41$ & 2.76 & $0.96-6.4 c$ \\
\hline Disease duration (year) & & & $8.8 \pm 6.8$ & 7.0 & $0.3-30.0$ \\
\hline Morning stiffness (minute) & & & $30.6 \pm 46.8$ & 10.0 & $0.0-180 . c$ \\
\hline
\end{tabular}

- Tests of model fit (misfit): In the tests of model fit, insignificant results of chi-square test with Bonferroni adjustment (item-trait interaction statistics) indicated that the data set fits to the Rasch model and verified the property of invariance across the trait. For residuals within the range of \pm 2.5 and with chi-square values below 10, the items were accepted to fit to the Rasch model.

- Unidimensionality: Whether the model sustained the assumption of unidimensionality or not was investigated by comparing the two subdimensions, which were formed as a result of residual principal component analysis and had a threshold of at least. ${ }^{12}$ The lack of any difference between the average of the two subdimensions and a confidence interval (CI) of 0.05 indicated unidimensionality.

- Differential item functioning (DIF): Two-way analysis of variance was used to test if there was any difference in the possibility of providing different answers to the same item by the individuals in different groups. The invariance in the item difficulty hierarchy among subgroups formed was based on age, sex, disease duration, and DAS28. Subgroups were: age ( $\leq$ median age of 54 years $\geq$ median), sex (female-male), disease duration ( $\leq$ median duration of seven years $\geq$ median) and DAS28 ( $\leq$ median DAS28 of 2.76 years $\geq$ median).

- The measurement's item and person detection were evaluated by comparing the mean person location level and the average item difficulty. In multiple tests for fit and DIF statistics, Bonferroni adjustment was applied. ${ }^{40}$

\section{RESULTS}

Demographic characteristics of the participants were presented in Table 1. Median Jamar grip strength of the dominant hand and non-dominant hand were measured as $15.4 \mathrm{~kg}$ (range, 2.7 to 39.3 ) and $14.6 \mathrm{~kg}$ (range, 0.0 to 36.7 ), respectively (Table 2). Grip strength of the

Table 2. Results of dominant hand and non-dominant hand

\begin{tabular}{|c|c|c|c|c|c|c|c|c|}
\hline & \multicolumn{3}{|c|}{ Dominant } & \multicolumn{3}{|c|}{ Non dominant } & \multirow[b]{2}{*}{ Z } & \multirow[b]{2}{*}{$p^{*}$} \\
\hline & Mean \pm SD & Median & Min-Max & Mean \pm SD & Median & Min-Max & & \\
\hline Jamar grip strength (kg) & $16.1 \pm 7.8$ & 15.4 & $2.7-39.3$ & $15.0 \pm 6.8$ & 14.6 & $0.0-36.7$ & 2.959 & 0.003 \\
\hline Pinch grip (kg) & $3.2 \pm 1.7$ & 2.83 & $0.50-10.00$ & $3.1 \pm 1.6$ & 2.83 & $0.00-8.66$ & 1.627 & 0.104 \\
\hline Lateral grip (kg) & $5.2 \pm 2.3$ & 4.75 & $0.90-11.33$ & $4.9 \pm 2.2$ & 4.73 & $0.00-10.90$ & 2.794 & 0.005 \\
\hline Tripod grip (kg) & $4.0 \pm 1.8$ & 3.58 & $1.00-9.50$ & $3.7 \pm 1.5$ & 3.48 & $0.00-8.36$ & 2.586 & 0.010 \\
\hline Nine Hole Peg Test (sec) & $21.7 \pm 4.2$ & 20.86 & $15.06-41.33$ & $22.2 \pm 4.8$ & 21.20 & $0.00-38.66$ & 2.652 & 0.008 \\
\hline
\end{tabular}




\begin{tabular}{|lccc|}
\hline \multicolumn{4}{|l}{ Table 3. Descriptive data of scales applied } \\
\hline Scales & Mean \pm SD & Median & Min-Max \\
\hline Duruoz Hand Index & $18.4 \pm 17.6$ & 11.50 & $0.00-67.00$ \\
Nottingham Health Profile total & $252.4 \pm 154.3$ & 236.27 & $0.00-543.76$ \\
Energy level & $63.7 \pm 36.1$ & 63.20 & $0.00-100.00$ \\
Pain & $50.0 \pm 37.3$ & 42.69 & $0.00-100.00$ \\
Emotional reactions & $40.3 \pm 32.0$ & 40.60 & $0.00-100.00$ \\
Sleep & $28.4 \pm 3.0$ & 19.75 & $0.00-100.00$ \\
Social isolation & $39.2 \pm 31.9$ & 38.82 & $0.00-100.00$ \\
Physical skill & $30.8 \pm 19.8$ & 21.99 & $0.00-78.70$ \\
\hline SD: Standard deviation; Min: Minimum; Max: Maximum. & & \\
\hline
\end{tabular}

dominant hand was higher compared to nondominant side $(z=2.959 ; p=0.003)$. Similarly, significant differences were found in favor of the dominant side in the aspects of lateral grip, tripod grip, and NHPT results $(p<0.05)$.

Internal consistency coefficient (Cronbach's alpha) value was identified as 0.953 for DHI. Identifiers related to the subdimensions of $\mathrm{DHI}$ and NHP were provided in Table 3.

The 27-item ABILHAND-RA scale was found to verify item invariance $\chi^{2}=36.476$; standard deviation $(\mathrm{SD})=27 ; \mathrm{p}=0.105]$. For the items 14 and 20, item function differences were detected with respect to DAS28. In items 7, 16, and 20 , order of the thresholds was problematic (disordered threshold). In the scale that fulfilled the unidimensionality assumption, residual correlations were quite high between some items. In order to resolve local dependence issue and to increase the fit to the Rasch model, subtests were formed using these items (Appendix 2). Item 20 , which $96 \%$ of the individuals marked "easy", was excluded (disordered threshold, uniform DIF and DAS28).

The remaining 18 items (7 subtests and 11 items) were found to sustain item invariance and fit to the Rasch model $\left(\chi^{2}=19.288 ; \mathrm{SD}=18\right.$, $p=0.374$, with Bonferroni correction, 0.003 significance level). Fit residuals were identified (range, -1.752 to 1.065 ) and items were found to fit to the model. Mean item fit residual value and mean person fit residual value were

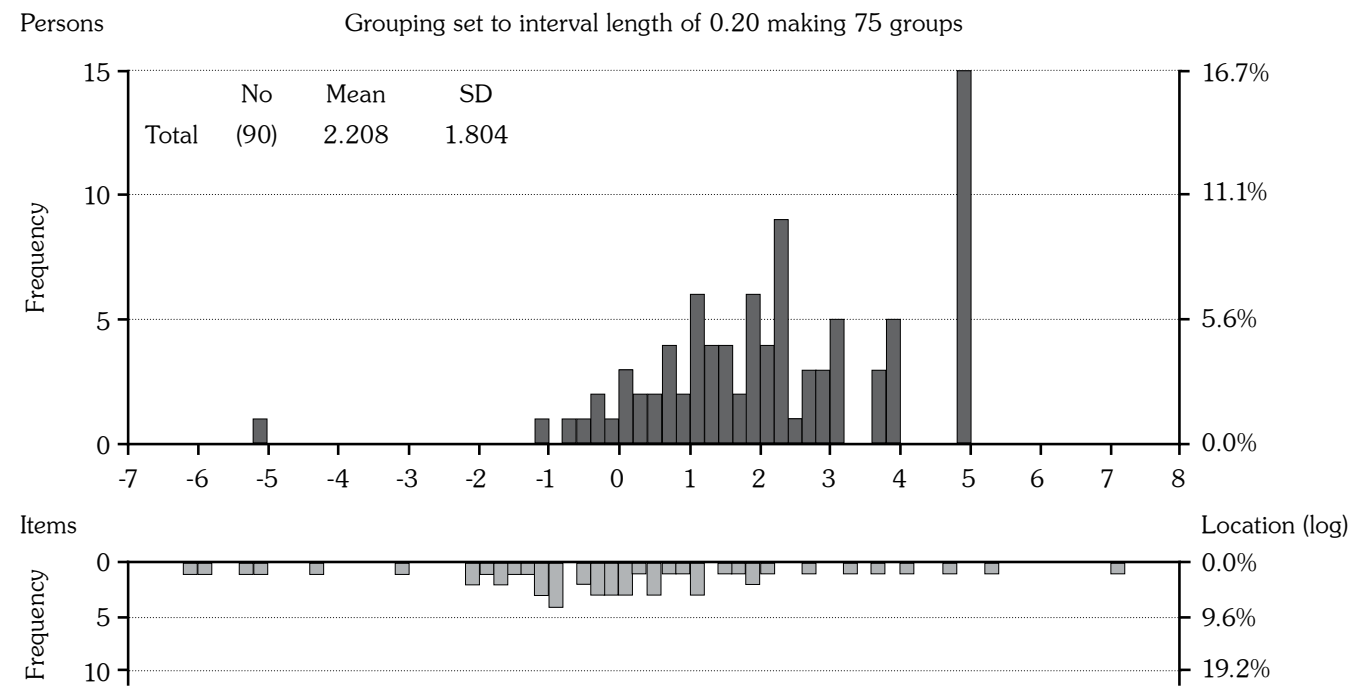

Figure 1. Person-item threshold distribution of Turkish version of ABILHAND questionnaire in individuals with rheumatoid arthritis. 
$-0.225 \pm 0.830$ and $-0.221 \pm 0.807$, respectively. The obtained residual standard errors were at an acceptable level $(<1.4)$. Item difficulty level was determined as minimum -1.700 logit and maximum 2.627 logit. An elevated logit value is an indicator for a more difficult item. Mean person location was $2.243 \pm 1.794$ and mean item location was $0.000 \pm 1.066$ (Figure 1). When residual correlations were analyzed, there was a borderline correlation only between item 9 and item 22 and no other values above 0.3 between the remaining items. There were no differences between the subsets identified after residual basic components analysis (set 1: SubTest (ST) 017, ST010, ST011, ST04, ST05, ST013; set 2: ST02, ST07, ST009, ST016, ST06) $(t=5.393$; proportion of significant tests: $5.6 \%, 95 \% \mathrm{CI}$ : 1.0\%-10.4\%). Unidimensionality assumption was fulfilled. There was no differential item functioning among the items in the aspects of age, sex, disease duration or DAS28 (at a significance level of 0.001 with Bonferroni correction).

Item difficulty levels and model fit statistics for the items that were used to determine the fit to the Rasch model for the ABILHAND-RA (TR) questionnaire were provided in Appendix 2. PSI was found as 0.808 for ABILHAND-RA (TR) questionnaire. It was demonstrated that reliability is sufficient enough for group comparisons.

In the ABILHAND-RA (TR) questionnaire, impossible was coded as "0", difficult as " 1 ", and easy was coded as " 2 ". In the 18-item ABILHAND-RA (TR) questionnaire, lower score indicates a more influenced hand. The correlations between demographic characteristics, dominant and non-dominant side grip strength scores, DHI score, NHP score, and the results of ABILHAND-RA (TR) questionnaire were provided in Table 4.

For females, the scores obtained from ABILHAND-RA (TR) were lower compared to males indicating more influence on females $(z=2.552 ; p=0.011)$. ABILHAND-RA (TR) scores were not correlated to age, hand dominancy, or duration of the disease ( $>00.05)$. There was an average but significant negative correlation between DAS28 and ABILHAND-RA (TR) $(\mathrm{rho}=-0.651 ; \mathrm{p}<0.001)$. As the severity of the disease increased, ABILHAND-RA (TR) scores seemed to decrease presenting more influence.

As the grip strength increased, ABILHANDRA (TR) scores significantly increased for both dominant and non-dominant sides $(p<0.05)$. As the NHPT hand function test duration increased, the ABILHAND-RA (TR) score decreased only for the dominant side $(p=0.021)$. However, the statistical difference was not significant for the non-dominant side ( $p>0.05$ ).

As expected, a very strong, linear, and negative correlation was found between $\mathrm{DHI}$ and ABILHAND-RA (TR) scores ( $\mathrm{rho}=-0.884$; $\mathrm{p}<0.001)$. As the individuals' DHI scores increased,

Table 4. Relationship between demographic and clinical variables and Turkish version of ABILHAND questionnaire in individuals with rheumatoid arthritis score $(\mathrm{n}=90)$

\begin{tabular}{|c|c|c|}
\hline Variables & Z; rho & $p$ \\
\hline Age & $\mathrm{rho}=-0.038$ & 0.720 \\
\hline Gender $(\mathrm{F}<\mathrm{M})$ & $z=-2.552$ & 0.011 \\
\hline Dominant hand (right left) & $z=-0.888$ & 0.374 \\
\hline Disease duration & rho $=-0.152$ & 0.154 \\
\hline DAS28 $(n=64)$ & $\mathrm{rho}=-0.651$ & $<0.001$ \\
\hline \multicolumn{3}{|l|}{ Grip strength } \\
\hline \multicolumn{3}{|l|}{ Dominant hand } \\
\hline Jamar grip strength & $\mathrm{rho}=0.632$ & $<0.001$ \\
\hline Pinch grip & rho $=0.468$ & $<0.001$ \\
\hline Lateral grip & $\mathrm{rho}=0.479$ & $<0.001$ \\
\hline Tripod grip & $\mathrm{rho}=0.475$ & $<0.001$ \\
\hline NHPT & $\mathrm{rho}=-0.244$ & 0.021 \\
\hline \multicolumn{3}{|l|}{ Non dominant hand } \\
\hline Jamar grip strength & $\mathrm{rho}=0.588$ & $<0.001$ \\
\hline Pinch grip & $\mathrm{rho}=0.434$ & $<0.001$ \\
\hline Lateral grip & $\mathrm{rho}=0.407$ & $<0.001$ \\
\hline Tripod grip & $\mathrm{rho}=0.439$ & $<0.001$ \\
\hline NHPT & $\mathrm{rho}=-0.093$ & 0.384 \\
\hline Duruoz Hand Index & $\mathrm{rho}=-0.884$ & $<0.001$ \\
\hline NHP total & $\mathrm{rho}=-0.616$ & $<0.001$ \\
\hline Energy level & $\mathrm{rho}=-0.532$ & $<0.001$ \\
\hline Pain & $\mathrm{rho}=-0.600$ & $<0.001$ \\
\hline Emotional reactions & rho $=-0.505$ & $<0.001$ \\
\hline Sleep & $\mathrm{rho}=-0.352$ & 0.001 \\
\hline Social isolation & $\mathrm{rho}=-0.428$ & $<0.001$ \\
\hline Physical skill & $\mathrm{rho}=-0.511$ & $<0.001$ \\
\hline \multicolumn{3}{|c|}{$\begin{array}{l}\text { DAS28: Disease Activity Score 28; NHPT: Nine Hole Peg Test; NHP: } \\
\text { Nottingham Health Profile; Z: Mann-Whitney U test; rho: Spearman's } \\
\text { rank correlation coefficient. }\end{array}$} \\
\hline
\end{tabular}


they obtained lower scores in ABILHAND-RA (TR) indicating a more influenced hand.

The relationship between NHP and ABILHAND-RA (TR) scores were average and the direction of the correlation was inverse (rho $=-0.616 ; p<0.001)$. Individuals with a higher NHP score indicating a lower level of health related quality of life also had lower ABILHANDRA (TR) score, again representing a more influenced hand.

In order to analyze test-retest reliability of ABILHAND-RA (TR) questionnaire, the correlation between the scores of two consecutive (at least seven days between the interviews) interviews was analyzed. Results indicated an excellent test-retest reliability (ICC: 0.921, 95\% CI: 0.882-0.947; $\mathrm{p}<0.001$ ).

\section{DISCUSSION}

The current study was conducted to test the validity and reliability of the ABILHAND-RA (TR). Following the exclusion of one item (item 20) and combining of highly correlated item couples (subsets), it was determined that the 18 -item ABILHAND-RA (TR) questionnaire sustains item invariance and fits to the Rasch model.

It is thought that the reason for the 96\% "easy" answer given for the highly correlated "Handling a four-color ballpoint pen with one hand" item is that this activity is commonly performed using thumb interphalangeal joint, though in RA, first carpometacarpal joint is more frequently involved than the former. ${ }^{41}$ As a result, item 20 in ABILHAND-RA (TR) is insufficient to differentiate hand skills of patients.

While manual ability is a measure that deals with a complex characteristic of human behavior, no one can expect all items and individuals to fit in a strictly mathematical model such as Rasch model. In ABILHAND-RA (TR) questionnaire, residual correlations were detected to be rather high. Thus, to resolve local dependence issue and to increase the fit to the Rasch model, subtests were formed using these items. ${ }^{42}$ Items with similar difficulty levels compared to other items are excluded as they show potential item redundancy. ${ }^{15}$ Based on our clinical expertise, these item couples (subsets) provide very little information related to the manual ability of an individual as they question activities that have similar difficulty level. For example, participants reported that the items "peeling onions" and "peeling potatoes with knife" and the items "taking a coin out of the pocket" and "grasping a coin on the table" were very similar.

Another observation related to these combined item couples (subsets) during the assessment of individuals with RA is that participants throughout their daily life performed them rarely. For example, female participants who constitute the majority of the participants in our sample reported that they rarely perform the items "using a screwdriver" and "screwing a nut on" in daily life; instead, they usually ask their partners to perform these activities.

In our study, ABILHAND-RA (TR) scores of female participants were significantly lower compared to males, likewise females were reported to be more affected than males. ${ }^{43,44}$ In the literature, a relationship was also expressed between disease activity and patient ability. ${ }^{45}$ Similar to the literature, DAS28 and ABILHAND-RA (TR) scores were inversely correlated at a moderate level. Furthermore, factors like age and handedness were also found to be correlated to the manual ability perceived by the individuals. ${ }^{46,47}$ The significant relationship between manual ability and grip strength presented in this study was also reported in a previous study. ${ }^{14}$ However, no relationship was detected between disease duration and ABILHAND-RA (TR) scores.

Measurements assessing functional disability in RA are increasingly used to evaluate treatment outcomes and disease progression. ${ }^{48,49}$ It is easier to monitor an individual's status quantitatively using purposeful activities which are meaningful for the individual when the measurements' items fulfill the necessary requirements of unidimensional measures. Most functional tests have no standards. They are commonly individual-centered measures and are devised to measure the perception of patients in a specific region. In assessing manual ability, ABILHAND targets patient skills decently. ${ }^{14}$ It is able to expose activities that are present in real life and important for the patients, but hard to detect in laboratory conditions. ${ }^{9}$ ABILHAND creates a possibility to behaviorally measure the 
ability in carrying out manual activities of the participants regardless of the pattern they use. ${ }^{14}$

Even though upper extremity disorders are significantly related to manual ability, the perceived difficulty in performing activities depends on other factors such as motivation and psychological condition. ${ }^{48}$ It should be noted that as a self-reported questionnaire, ABILHAND-RA (TR) gathers subjective that and may include personal attitudes and beliefs that may cause bias and modify the real situation. The answer alternatives in the questionnaire -easy, difficult, impossible- are not very sensitive and the difference between is obscure. This issue makes it harder to implement the questionnaire and affects measurement variability. Other investigators also pointed out to this disadvantage previously. ${ }^{13,50,51}$ In addition, a recent study has advocated that items that are more difficult to perform should be included in the questionnaire. ${ }^{50}$ The ABILHAND-RA (TR) questionnaire is not particularly sensitive to the answers. If ABILHAND-RA (TR) is made more sensitive by addition of a new section to the response section in the evaluation of manual ability, it may become more appropriate to differentiate the progression of individuals even in small sample sizes to show the efficacy of intervention methods in longitudinal studies.

Keeping these limitations in mind, the available items in ABILHAND-RA (TR) seem to work fairly well. The intra-class correlation coefficient (ICC $=921$ ) obtained from test-retest validation analysis is high which indicates that ABILHAND-RA (TR) questionnaire is sufficiently sensitive and appropriate enough to detect differences between individuals with RA who exhibit a wide range of functional levels. The observed invariance supports utilization of ABILHAND-RA (TR) in clinical settings (in clinical assessments, rehabilitation interventions, and evaluation of recovery). Our sample represents the population well enough as it includes individuals with RA having different levels of functional status. Following this validation, future work is needed to investigate whether item hierarchy is sustained throughout the rehabilitation process.

In conclusion, the Rasch analysis conducted in this study allowed to develop an 18-item
ABILHAND-RA (TR) questionnaire presenting unidimensionality and appropriate internal construct validity. ABILHAND-RA (TR) was found to be clinically valid, reliable, and sensitive enough to be used in clinical evaluations, rehabilitation interventions, and for progression follow-up in individuals with RA.

\section{Declaration of conflicting interests}

The authors declared no conflicts of interest with respect to the authorship and/or publication of this article.

\section{Funding}

The authors received no financial support for the research and/or authorship of this article.

\section{REFERENCES}

1. Fleming A, Benn RT, Corbett M, Wood PH. Early rheumatoid disease. II. Patterns of joint involvement. Ann Rheum Dis 1976;35:361-4.

2. Hochberg MC. Adult and juvenile rheumatoid arthritis: current epidemiologic concepts. Epidemiol Rev 1981;3:27-44.

3. Akkoc N, Akar S. Epidemiology of rheumatoid arthritis in Turkey. Clin Rheumatol 2006;25:560-1.

4. Nieman DC. Exercise soothes arthritis: joint effects. ACSMs Health Fit J 2000;4:20-28.

5. Adams J, Burridge J, Mullee M, Hammond A, Cooper C. Correlation between upper limb functional ability and structural hand impairment in an early rheumatoid population. Clin Rehabil 2004;18:405-13.

6. Guralnik JM, Ferrucci L. Assessing the building blocks of function: utilizing measures of functional limitation. Am J Prev Med 2003;25:112-21.

7. Hudak PL, Amadio PC, Bombardier C. Development of an upper extremity outcome measure: the DASH (disabilities of the arm, shoulder and hand) [corrected]. The Upper Extremity Collaborative Group (UECG). Am J Ind Med 1996;29:602-8.

8. Penta M, Thonnard JL, Tesio L. ABILHAND: a Rasch-built measure of manual ability. Arch Phys Med Rehabil 1998;79:1038-42.

9. Penta M, Tesio L, Arnould C, Zancan A, Thonnard $\mathrm{JL}$. The ABILHAND questionnaire as a measure of manual ability in chronic stroke patients: Rasch-based validation and relationship to upper limb impairment. Stroke 2001;32:1627-34.

10. Arnould C, Penta M, Renders A, Thonnard JL. ABILHAND-Kids: a measure of manual ability in children with cerebral palsy. Neurology 2004;63:1045-52.

11. Burger H, Franchignoni F, Kotnik S, Giordano A. A Rasch-based validation of a short version of ABILHAND as a measure of manual ability in adults 
with unilateral upper limb amputation. Disabil Rehabil 2009;31:2023-30.

12. Vandervelde L, Van den Bergh PY, Penta M, Thonnard JL. Validation of the ABILHAND questionnaire to measure manual ability in children and adults with neuromuscular disorders. J Neurol Neurosurg Psychiatry 2010;81:506-12.

13. Barrett LE, Cano SJ, Zajicek JP, Hobart JC. Can the ABILHAND handle manual ability in MS? Mult Scler 2013;19:806-15.

14. Durez P, Fraselle V, Houssiau F, Thonnard JL, Nielens H, Penta M. Validation of the ABILHAND questionnaire as a measure of manual ability in patients with rheumatoid arthritis. Ann Rheum Dis 2007;66:1098-105.

15. Tesio L. Measuring behaviours and perceptions: Rasch analysis as a tool for rehabilitation research. J Rehabil Med 2003;35:105-15.

16. Wright BD, Masters GN. Rating Scale Analysis. Chicago: Mesa Press; 1982.

17. Bond TG, Fox CM. Applying The Rasch Model: Fundamental Measurement in the Human Sciences. Mahwah: Routledge; 2001.

18. Grimby G, Tennant A, Tesio L. The use of raw scores from ordinal scales: time to end malpractice? J Rehabil Med 2012;44:97-8.

19. Küçükdeveci AA, Sahin $H$, Ataman S, Griffiths $\mathrm{B}$, Tennant A. Issues in cross-cultural validity: example from the adaptation, reliability, and validity testing of a Turkish version of the Stanford Health Assessment Questionnaire. Arthritis Rheum 2004;51:14-9.

20. Arnett FC, Edworthy SM, Bloch DA, McShane DJ, Fries JF, Cooper NS, et al. The American Rheumatism Association 1987 revised criteria for the classification of rheumatoid arthritis. Arthritis Rheum 1988;31:315-24.

21. Prevoo ML, van 't Hof MA, Kuper $\mathrm{HH}$, van Leeuwen MA, van de Putte LB, van Riel PL. Modified disease activity scores that include twenty-eight-joint counts. Development and validation in a prospective longitudinal study of patients with rheumatoid arthritis. Arthritis Rheum 1995;38:44-8.

22. Mathiowetz V, Weber K, Volland G, Kashman N. Reliability and validity of grip and pinch strength evaluations. J Hand Surg Am 1984;9:222-6.

23. Mathiowetz V, Weber K, Kashman N, Volland G. Adult norms for nine hole peg test of finger dexterity. The Occup Ther J Res 1985;5:24-38.

24. Duruöz MT, Poiraudeau S, Fermanian J, Menkes CJ, Amor B, Dougados M, et al. Development and validation of a rheumatoid hand functional disability scale that assesses functional handicap. J Rheumatol 1996;23:1167-72.

25. Hunt SM, McKenna SP, McEwen J, Backett EM, Williams J, Papp E. A quantitative approach to perceived health status: a validation study. J Epidemiol Community Health 1980;34:281-6.
26. Kücükdeveci AA, McKenna SP, Kutlay S, Gürsel Y, Whalley D, Arasil T. The development and psychometric assessment of the Turkish version of the Nottingham Health Profile. Int $\mathrm{J}$ Rehabil Res 2000;23:31-8.

27. Beaton DE, Bombardier C, Guillemin F, Ferraz MB. Guidelines for the process of cross-cultural adaptation of self-report measures. Spine (Phila Pa 1976) 2000;25:3186-91.

28. Wild D, Grove A, Martin M, Eremenco S, McElroy S, Verjee-Lorenz A, et al. Principles of Good Practice for the Translation and Cultural Adaptation Process for Patient-Reported Outcomes (PRO) Measures: report of the ISPOR Task Force for Translation and Cultural Adaptation. Value Health 2005;8:94-104.

29. Nunnally JC, editor. Psychometric Theory. New York: McGrawHill; 1978.

30. Rasch G. Probabilistic Models For Some Intelligence and Attainment Tests. Chicago: University of Chicago Press; 1960.

31. Masters GN. A Rasch model for partial credit scoring. Psychometrika 1982;47:149-74.

32. Haywood KL, M Garratt A, Jordan K, Dziedzic K, Dawes PT. Disease-specific, patient-assessed measures of health outcome in ankylosing spondylitis: reliability, validity and responsiveness. Rheumatology (Oxford) 2002;41:1295-302.

33. Fisher WP. Reliability statistics. Rasch Meas Trans 1992;6:238.

34. Streiner DL, Norman GR. Health Measurement Scales. A Practical guide to Their Development and Use. 2nd ed. New York: Oxford Medical Publications; 1995.

35. Nunnally JC, Bernstein IH. Psychometric Theory. 3rd ed. New York: McGrawHill; 1994.

36. Shrout PE, Fleiss JL. Intraclass correlations: uses in assessing rater reliability. Psychol Bull 1979;86:420-8.

37. Koo TK, Li MY. A Guideline of Selecting and Reporting Intraclass Correlation Coefficients for Reliability Research. J Chiropr Med 2016;15:155-63.

38. Tennant A, Conaghan PG. The Rasch measurement model in rheumatology: what is it and why use it? When should it be applied, and what should one look for in a Rasch paper? Arthritis Rheum 2007;57:1358-62.

39. Wright BD. Local dependency, correlations and principal components. Rasch Meas Trans 1996;10:509-11.

40. Bland J, Altman DG. Multiple significance tests: the Bonferroni method. BMJ 1995;310:170.

41. Dickson RA, Morrison JD. The pattern of joint involvement in hands with arthritis at the base of the thumb. Hand 1979;11:249-55.

42. Reeve BB, Hays RD, Bjorner JB, Cook KF, Crane PK, Teresi JA, et al. Psychometric evaluation and calibration of health-related quality of life item banks: plans for the Patient-Reported Outcomes Measurement Information System (PROMIS). Med Care 2007;45:22-31. 
43. Tengstrand B, Ahlmén M, Hafström I. The influence of sex on rheumatoid arthritis: a prospective study of onset and outcome after 2 years. J Rheumatol 2004;31:214-22.

44. Welsing PM, van Gestel AM, Swinkels HL, Kiemeney LA, van Riel PL. The relationship between disease activity, joint destruction, and functional capacity over the course of rheumatoid arthritis. Arthritis Rheum 2001;44:2009-17.

45. Drossaers-Bakker KW, de Buck M, van Zeben D, Zwinderman AH, Breedveld FC, Hazes JM. Longterm course and outcome of functional capacity in rheumatoid arthritis: the effect of disease activity and radiologic damage over time. Arthritis Rheum 1999;42:1854-60.

46. Dellhag B, Burckhardt CS. Predictors of hand function in patients with rheumatoid arthritis. Arthritis Care Res 1995;8:16-20.

47. Vliet Vlieland TP, van der Wijk TP, Jolie IM, Zwinderman $\mathrm{AH}$, Hazes JM. Determinants of hand function in patients with rheumatoid arthritis. $\mathrm{J}$ Rheumatol 1996;23:835-40.
48. Klareskog L, van der Heijde D, de Jager JP, Gough A, Kalden J, Malaise M, et al. Therapeutic effect of the combination of etanercept and methotrexate compared with each treatment alone in patients with rheumatoid arthritis: double-blind randomised controlled trial. Lancet 2004;363:675-81.

49. Ekstrand E, Lindgren I, Lexell J, Brogårdh C. Testretest reliability of the ABILHAND questionnaire in persons with chronic stroke. PM R 2014;6:324-31.

50. Gustafsson S, Stibrant Sunnerhagen K, DahlinIvanoff S. Occupational therapists' and patients' perceptions of ABILHAND, a new assessment tool for measuring manual ability. Scand J Occup Ther 2004;11:107-17.

51. Keystone EC, Kavanaugh AF, Sharp JT, Tannenbaum H, Hua Y, Teoh LS, et al. Radiographic, clinical, and functional outcomes of treatment with adalimumab (a human anti-tumor necrosis factor monoclonal antibody) in patients with active rheumatoid arthritis receiving concomitant methotrexate therapy: a randomized, placebo-controlled, 52-week trial. Arthritis Rheum 2004;50:1400-11.

Appendix 1. Turkish version of ABILHAND questionnaire in individuals with rheumatoid arthritis

\begin{tabular}{|c|c|c|c|c|c|}
\hline & Aşağıdaki aktiviteler ne kadar ZOR? & Mümkün değil & Zor & Kolay & Fikrim Yok \\
\hline 1 & Kurşun kalemi açmak & & & & \\
\hline 2 & İğneye iplik geçirmek & & & & \\
\hline 3 & Bıçakla patates soymak & & & & \\
\hline 4 & Soğan soymak & & & & \\
\hline 5 & Kavanozun kapağını açmak & & & & \\
\hline 6 & Et kesmek & & & & \\
\hline 7 & Masanın üstünde duran bir bozuk parayı almak & & & & \\
\hline 8 & Anahtar deliğindeki anahtarı çevirmek & & & & \\
\hline 9 & Bir cümle yazmak & & & & \\
\hline 10 & Çerez paketini açmak & & & & \\
\hline 11 & Hediye paketlemek & & & & \\
\hline 12 & Çıtçıtı kapatma (mont, çanta vb.) & & & & \\
\hline 13 & Birinin tırnaklarını kesmek & & & & \\
\hline 14 & Birinin tırnaklarını törpülemek & & & & \\
\hline 15 & Birinin saçını fırça ile taramak & & & & \\
\hline 16 & Ampul takmak & & & & \\
\hline 17 & Tornavida kullanmak & & & & \\
\hline 18 & Somunu çevirerek sıkıştırmak & & & & \\
\hline 19 & Zimba kullanmak & & & & \\
\hline 20 & Basmalı tükenmez kalemi kullanmak & & & & \\
\hline 21 & Musluk açmak & & & & \\
\hline 22 & Bir teneke kutuyu almak (kola kutusu gibi) & & & & \\
\hline 23 & Birinin saçını taramak & & & & \\
\hline 24 & Cepten bozuk para çıarmak & & & & \\
\hline 25 & Bir ceketin fermuarını çekmek & & & & \\
\hline 26 & Bir şişenin kapağını açmak & & & & \\
\hline 27 & Çivi çakmak & & & & \\
\hline
\end{tabular}


Appendix 2. Fit of Turkish version of ABILHAND questionnaire in individuals with rheumatoid arthritis items for Rasch model (18 items)

\begin{tabular}{|c|c|c|c|c|c|c|}
\hline Item & ABILHAND-RA Items & $\begin{array}{l}\text { Location } \\
\text { logits }\end{array}$ & $\begin{array}{l}\text { Standard } \\
\text { error }\end{array}$ & $\begin{array}{l}\text { Individual item } \\
\text { fit residual }\end{array}$ & $\chi^{2}$ & $p$ \\
\hline ST03 & $\begin{array}{l}12 \text { Çıtçıtı kapatma (mont. çanta vb) } \\
25 \text { Bir ceketin fermuarını çekmek }\end{array}$ & -1.700 & 0.205 & 0.119 & 0.069 & 0.793 \\
\hline ST012 & 8 Anahtar deliğindeki anahtarı çevirmek & -1.281 & 0.314 & -0.811 & 0.447 & 0.504 \\
\hline ST05 & $\begin{array}{l}7 \text { Masanın üstünde duran bir bozuk parayı almak } \\
24 \text { Cepten bozuk para çıkarmak }\end{array}$ & -1.207 & 0.192 & 0.069 & 0.409 & 0.522 \\
\hline ST06 & $\begin{array}{l}15 \text { Birinin saçını fırça ile taramak } \\
23 \text { Birinin saçını taramak }\end{array}$ & -1.069 & 0.198 & -0.291 & 0.043 & 0.836 \\
\hline ST017 & 22 Bir teneke kutuyu almak (kola kutusu gibi) & -0.868 & 0.281 & -1.053 & 2.787 & 0.095 \\
\hline ST008 & 1 Kurşun kalem açmak & -0.653 & 0.357 & -1.596 & 2.406 & 0.121 \\
\hline ST013 & 9 Bir cümle yazmak & -0.489 & 0.275 & -1.125 & 0.773 & 0.379 \\
\hline ST015 & 11 Hediye paketlemek & -0.256 & 0.275 & -1.752 & 2.330 & 0.127 \\
\hline ST01 & $\begin{array}{l}3 \text { Biçakla patates soymak } \\
4 \text { Soğan soymak }\end{array}$ & 0.136 & 0.151 & -0.483 & 0.020 & 0.887 \\
\hline ST014 & 10 Çerez paketini açmak & 0.189 & 0.223 & 0.647 & 0.985 & 0.321 \\
\hline ST07 & $\begin{array}{l}17 \text { Tornavida kullanmak } \\
18 \text { Somunu çevirerek sıkıştırmak } \\
21 \text { Musluk açmak }\end{array}$ & 0.341 & 0.205 & 0.138 & 0.650 & 0.420 \\
\hline ST009 & 2 İğneye iplik geçirmek & 0.346 & 0.216 & 1.065 & 2.501 & 0.114 \\
\hline ST04 & $\begin{array}{l}19 \text { Zımba kullanmak } \\
27 \text { Çivi çakmak }\end{array}$ & 0.433 & 0.326 & -0.207 & 0.306 & 0.580 \\
\hline ST02 & $\begin{array}{l}13 \text { Birinin tırnaklarını kesmek } \\
14 \text { Birinin tırnaklarını törpülemek }\end{array}$ & 0.524 & 0.185 & 0.602 & 1.532 & 0.216 \\
\hline ST016 & 16 Ampul takmak & 0.724 & 0.268 & 1.061 & 1.452 & 0.228 \\
\hline ST018 & 26 Bir şişenin kapağını açmak & 0.890 & 0.199 & 0.002 & 0.638 & 0.424 \\
\hline ST011 & 6 Et kesmek & 1.312 & 0.211 & -0.688 & 1.513 & 0.219 \\
\hline ST010 & 5 Kavanozun kapağını açmak & 2.627 & 0.207 & 0.250 & 0.427 & 0.513 \\
\hline
\end{tabular}

